\title{
Answering a century old riddle: brachydactyly type A1
}

\author{
Bo $\mathrm{GAO}^{2,3}$, Lin $\mathrm{HE}^{1,2}$ \\ ${ }^{1}$ Institute for Nutritional Sciences, Shanghai Institutes for Biological Sciences, Chinese Academy of Sciences, Shanghai \\ 200031, China. \\ ${ }^{2}$ Neuropsychiatric and Human Genetics Group, Bio-X Life Science Research Center, Shanghai Jiaotong University, Shanghai \\ 200030, China. \\ ${ }^{3}$ Department of Biochemistry, Faculty of Medicine, The University of Hong Kong, Hong Kong, China.
}

\begin{abstract}
In 1903, Farabee analyzed the heredity of the human digital malformation, brachydactyly, the first recorded disorder of the autosomal dominant Mendelian trait. In 1951, Bell classified this type of brachydactyly as type A1 (BDA1). Over 100 cases from different ethnic groups have so far been reported. However, the real breakthrough in identifying the cause of BDA1 has only taken place in the last few years with the progress of the mapping and identification of one of the genes responsible for this disorder, thus providing an answer for a century old riddle. In this article, we attempt to review the current state of knowledge on the genetic features of BDA1 with its century-old history and signalling pathway of IHH, and also discuss genotype-phenotype correlation not only of BDA1, but also of all types of brachydactyly.
\end{abstract}

Keywords: Brachydactyly, IHH, GDF5, ROR2, BMPRIB.

\section{History and Introduction}

Mendel's law has shaped the whole study of genetics since Gregor Mendel published his work (1865) based on his famous pea plant experiment. However, it took thirtyfive years for the scientific community at that time to appreciate his pioneering work. Three years after the rediscovery of Mendel's law by De Vries, Correns and Von Tschermak in 1900, the theory was first applied to humans by William Curtis Farabee (1865-1925), a graduate student of Castle, the director of the Bussey Institute at Harvard University and it provided the background for much of the early work in human genetics. Farabee analyzed the heredity of a human hand malformation, brachydactyly, the first disorder to be described as an autosomal dominant Mendelian trait, as part of his doctoral dissertation in 1903[1] (Fig 1). Members of five generations in one family from Pennsylvania were affected with half of the offspring having the anomaly (more than 30 cases). Farabee concluded that "the present case demonstrates that the law operates in man as in plants and lower animals. The abnormality is shown here to be a dominant character." Looking back on the last one hundred years, the progress in the field of human genetics stands out as a monumental achievement. Over 1,000 phenotypes

${ }^{*}$ Correspondence: Lin HE

Tel: +86-21-64717740, Fax: +86-21-64717740

E-mail: helin@nhgg.org

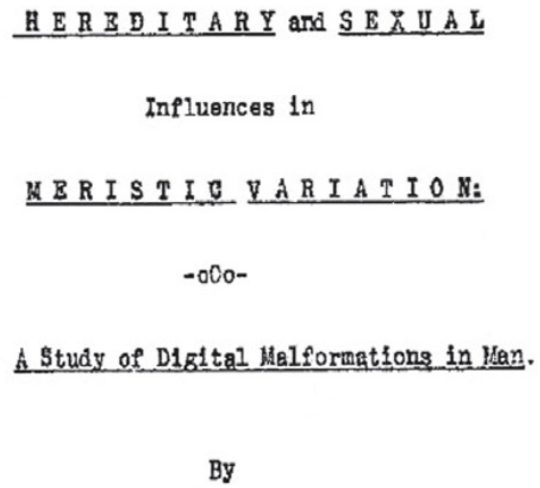

Hay 1, 1903.

Filliam C. Farabee.

Fig 1. The copy of original top page of Farabee's doctoral dissertation.

have been identified as gene related (OMIM). Understanding the history and current advances in the studies of Farabee's brachydactyly may signal our progress in this field due to its special position that have been even cited in many genetic textbooks.

Drinkwater (1908[2], 1912[3] and 1915[4]) performed a comprehensive study of families with Farabee type brachydactyly, and this was subsequently classified as Brachydactyly type A1 (BDA1) by Bell in 1951[5]. Haws and Mckusick in 1963 followed up the study of Farabee's Brachydactyly family[6]. Since then, many BDA1 families 
or individuals have been reported (Temtamy 1978[7]; Laporte 1979[8]; Piussan 1983[9]; Tsukahara 1989[10]; Fukushima 1995[11]; Mastrobattista 1995[12]; Slavotinek 1998[13]; Raff 1998[14]; Armour 2000[15]; Yang 2000 [16]; Gao 2001[17]; Hollander 2001[18]; Giordano 2003 [19]). Up to now, over 100 BDA1 family cases covering different ethnic groups, including Caucasian, African American and Chinese, have been reported in medical journals.

Some scientists tried to identify the gene responsible for BDA1, which can lead to unraveling the link between gene regulation and morphogenesis of the digits, and contribute to developmental biology. Mastrobattista[12](1995) excluded a number of candidate genes in his study of two families with multiple affected members. Yang et al[16] (2000) and Gao et al[17] (2001) went further by mapping and identifying the gene for Brachydactyly type A1, IHH (Indian hedgehog), using their own samples. Their works have shed light on the BDA1-causing gene with leading to a number of papers published.

\section{Clinical features (In chronological order, also see supplement in phenotype classification)}

Farabee's brachydactyly was characterized by shortness of the middle phalanges of all digits in the hands and feet, shortness of the proximal phalanx of the first digit, and occasional fusion of the middle and terminal phalanges. In some individuals, the metacarpals were also short. Affected family members had short stature compared to normal family members. In the 1950 s, three surviving members of Farabee's original family were revisited by Haws and McKusick (1963)[6]. Two family members were found to have more generalized skeletal abnormalities but no epiphyses were demonstrable in the middle phalanges of affected children.

Descendents of Drinkwater's first and third families in 1908[2] and 1915[4] were studied by Slavotinek (1998) [13] and McCready (2002)[20], respectively. Both families had typical characteristics of Farabee's brachydactyly but considerable inter- and intrafamilial heterogeneities were observed. In some individuals, BDA1 occurred as an isolated malformation. Others also experienced musculoskeletal abnormalities, scoliosis, nystagmus, and/or developmental delay. Short stature among affected individuals was not consistent. Drinkwater's speculation (1915)[4] that the two families were related has recently been confirmed by the identification of a common haplotype[20], and both families are likely to be related to the Farabee's family through an individual named Benjamin Hyde. The family studied by Farabee migrated from England to Pennsylvania while the family studied by Drinkwater remained in England. However, this relationship was never proven and questioned by Hawes and
Mckusick in 1963[6].

Bell (1951)[5] classified inherited brachydactyly into five types, A, B, C, D, E on the basis of malformation of the digits and further subdivided type A into A1, A2 and A3 subtypes. In types A2 and A3, the shortening is confined to the middle phalanx of the index finger and digit 5, respectively. McKusick 1975[21] added types A4 where the middle phalanges of digits 2 and 5 are short and A5 where the middle phalanges are missing, but both falls into Bell's type A1 as reclassified by Fitch (1979)[22]. Fitch's reclassification of A1 looks more comprehensive. For example, the hands are broad, with proportionate shortening of all the digits; all the hand bones may be shorter than those in normal hands but the middle phalanges and the proximal $1^{\text {st }}$ phalanges are the most severely shortened because they are the last to ossify. Wherever middle phalanges are reduced or missing, no distal interphalangeal joints are formed.

In 1978, Temtamy reported BDA1 phenotypes in a black family[7]; in 1979, Laporte reported five members of a family with classical BDA1[8]; and in 1983, Piussan described several women in a family with both BDA1 and some other phenotypes, such as, ankylosis of the thumbs, mental retardation and short stature[9]. In another study of six years later, Tsukahara (1989) reported BDA1 accompanying many abnormalities and mental retardation [10]. A combination of BDA1 and Klippel-Feil anomaly was described by Fukushima in 1995[11]; Mastrobattista in 1995 reported two typical BDA1 families of Scandinavian and Mexican descent, respectively[12]; Raff in 1998 reported a three-generation family with a triad of BDA1, abnormal menisci, and scoliosis segregate as an autosomal dominant osteochondrodysplasia[14]. Den Hollander in 2001 did the first prenatal diagnosis of brachydactyly type A1 for a pregnant woman with this phenotype[18]. Giordano in 2003 described an Italian BDA1 family with three affected members in three different generations[19].

Armour[15] in 2000 made an assessment of a Canadian family with mild BDA1. The principal characterizations of these patients showed shortened middle and distal phalanges, proximal $1^{\text {st }}$ phalanges, and $5^{\text {th }}$ metacarpals. No phalanges fusion was found. The feet were similarly involved. Coned epiphyses or evidence of premature fusion of the growth plates involving the middle phalanges was common in the children (Fig 2A). Relatively short stature in affected members was also noted.

Yang et al [16] in 2000 described two large Chinese BDA1 families, of which family I showed all the manifestations that are common to other reports reviewed by Fitch 1979[22]. However, several affected members had some manifestations beyond Fitch's description including the shortened distal phalanges, metacarpals and proximal 
A

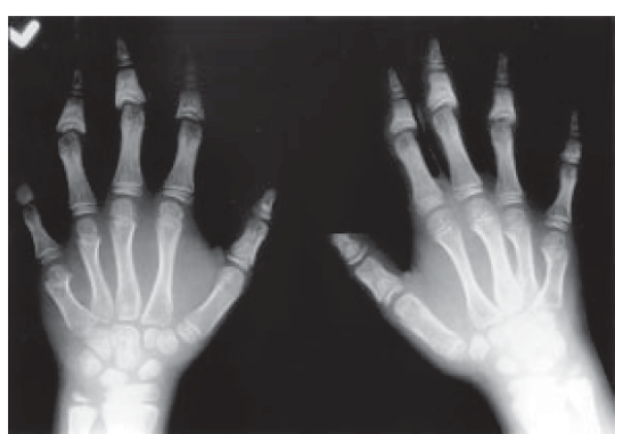

C

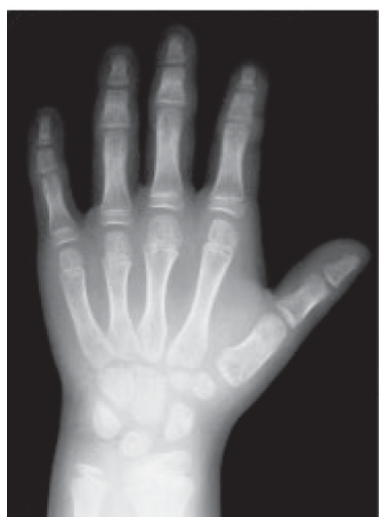
72(4):1040-6).
B

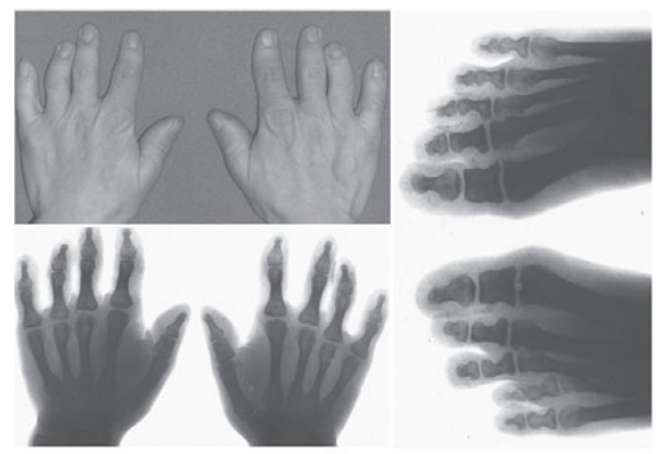

Fig 2. (A) Affected child with mild BDA1 has short and cone shaped middle phalanges (With permission from Alasdair Hunter and BMJ Publishing Group, J Med Genet 2000; 37:292-6). (B) Phenotype of typical BDA1. Middle phalanges are missing or fused to distal ones (With permission from Nature Publishing Group, Nat Genet 2001; 28:386-8). (C) Coned shaped epiphyses are present in the pronounced short middle phalanges of affected member with ACFD (With permission from Geert Mortier, Am J Hum Genet 2003;

phalange of digit 5 . The phenotypes in family II were similar but more severe than those in family I, of which most affected members had all middle phalanges missing. Affected members in both families had normal stature and mental status but with different origins as demonstrated by a lack of common haplotype. One year later, Gao et al [17] (2001), working in the same lab as Yang, recruited a new BDA1 family in the study. In x-ray analysis, it showed that the hand bones of affected members had the same morphology (Fig 2B) as those seen in families studied by Yang et al (2000)[16] but short stature in affected members was a significant feature.

Recently, a new autosomal recessive syndrome, namely Acrocapitofemoral Dysplasia (ACFD) was found in four children, also showing BDA1 phenotype (Mortier 2003) [23]. The clinical phenotype was characterized by short stature with short limbs, brachydactyly, relatively large head, and narrow thorax with pectus deformities. In the hands of those children, tubular bones, especially the middle phalanges, were shortened (Fig 2C). In the hips, a characteristic egg-shaped femoral head was attached to a very short femoral neck (Fig 3). These deformities were considered to be caused by cone-shaped epiphyses observed in the hands, the proximal part of the femur, and, to a

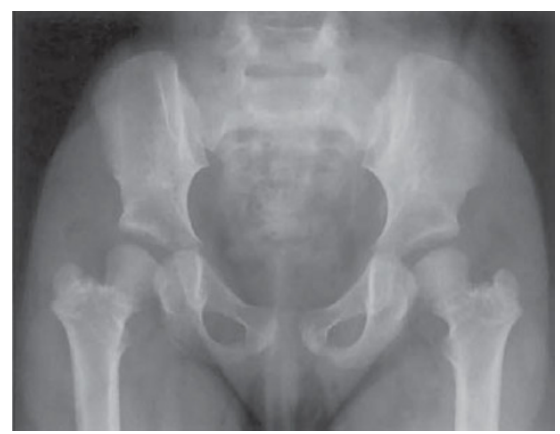

Fig 3. Radiograph of the pelvis in affect member with ACFD shows coax vara with egg-shaped femoral head and very short femoral neck (With permission from Geert Mortier, Am J Hum Genet 2003; 72 (4):1040-6).

variable degree at the shoulders, knees, and ankles. Only mild shortening of middle phalanges were observed in some parents of the affected subjects.

\section{Molecular basis}

The gene for BDA1 in two Chinese families (Yang 2000)[16] was first localized to an $8.1 \mathrm{cM}$ interval on 


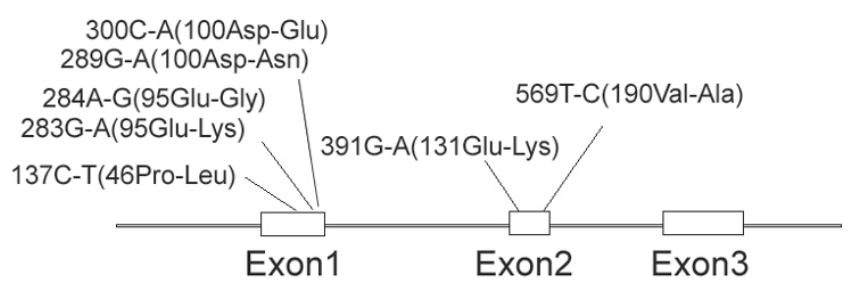

Fig 4. The mutational spectrum of human $I H H$.

chromosome 2q35-q36 flanked by markers D2S2248 and $D 2 S 360$, with a maximum lod score of 6.59 . Haplotype analysis suggested that the two families were not related. Interestingly, a second locus at 5p13.2-p13.3 in a Canadian family was identified by Armour in 2002[24], with a maximum lod score of 6.91 at D5S477. Haplotype analysis provided evidence of the gene within an $11 \mathrm{cM}$ critical region. Mapping to a new locus indicates that BDA1 is genetically heterogeneous. Very recently, Kirkpatrick (2003) [25] suggested the existence of a third locus for BDA1 in a Scandinavian family reported by Mastrobattista in 1995 [12].

Mastrobattista[12] examined several candidate genes including $H O X D, M S X 1, M S X 2, F G F 1$, and $F G F 2$ but did not find any evidence of linkage. Until the year of 2000 , the gene for BDA1 was successfully mapped to a narrow defined region of 2q35-q36 by Yang et al (2000)[16]. The $I H H$ gene located in this region is known to mediate condensation, growth and differentiation of cartilage[26] from the experimental results of $\mathrm{Ihh}^{-/}$knockout mouse with foreshortened forelimbs, unsegmented and uncalcified digits[27]. These all support $I H H$ as a strong candidate gene for BDA1. Eventually, in 2001, this prediction was well favored by identification of three mutations in three unrelated Chinese BDA1 families, of which two had previously been shown to be linked to 2q35-q36[17].

IHH belongs to the Hedgehog family, which is a conserved signalling family in vertebrates and some invertebrates, and has two structurally highly similar members, SHH (Sonic hedgehog) and DHH (Desert hedgehog)[28], with about $60 \%$ of overall amino acid and about $80 \%$ of the $\mathrm{N}$-terminal domain identity, respectively. $I H H$ contains three exons and translates 411 amino acids. Naturally, the hedgehog protein precursor of approximately $45 \mathrm{kD}$ undergoes autocatalytic internal cleavage to yield a $25 \mathrm{kD} \mathrm{C}$ terminal domain that is responsible for auto-cleavage and an approximately $20 \mathrm{kD} \mathrm{N}$-terminal domain[29], modified by cholesterol on C-terminus and palmitic acid on Nterminus[30,31], which has all known signalling activities. These hydrophobic moieties are thought to anchor Hedgehog on the cell surface of Hedgehog-producing cells[32].

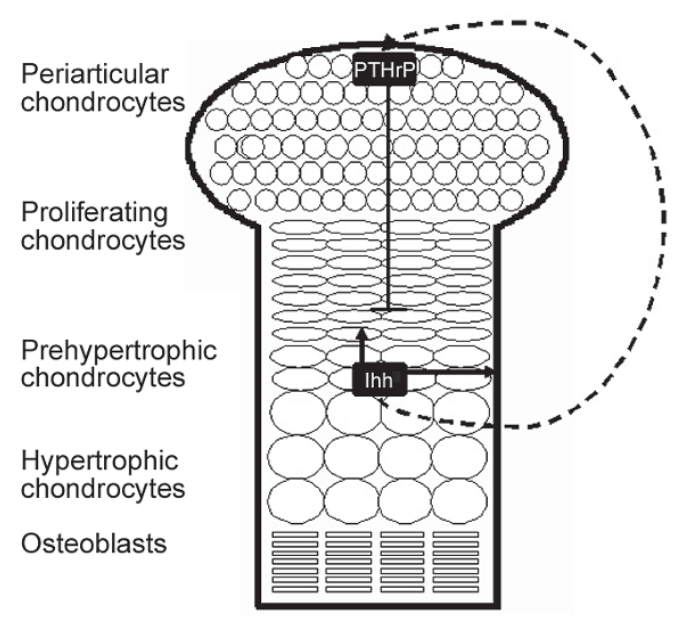

Fig 5. Ihh/PTHrP negative-feedback loop.

Gao et al [17] (2001) identified three heterozygous missense mutations in the region encoding the $\mathrm{N}$-terminal signalling domain in affected members of three Chinese families. Since then, the same or different dominant mutations in the same gene have been either confirmed or identified by McCready (2002)[20], Kirkpatrick (2003) [25] and Giordano (2003)[19] in different populations. Essen-tially, 5 different missense heterozygous mutations, affecting just 3 different amino acids, have been identified in 6 unrelated families (Fig 4). These are: (1) G283A resulting in Glu95Lys in a Chinese family[17]; (2) A284G resulting in Glu95Gly in a Mexican family[25]; (3) G298A resulting in Asp100Asn in both an Italian family and a Canadian family[19, 20]; (4) C300A resulting in Asp100Glu in a Chinese family[17]; (5) G391A resulting in Glu131Lys in a Chinese family[17]. It demonstrates that these highly conserved amino acids are important for the functioning of IHH in digital development and morphogenesis. Interestingly, another recent publication shows that homozygous $\mathrm{IHH}$ mutations can result in more severe phenotype[33]. Recently, two missense mutations (C137T resulting in Pro46Leu and T569C resulting in Val190Ala) in the signalling domain of IHH have been identified by Hellemans (2003) in two Acrocapitofemoral Dysplasia families[33]. Both mutant amino acids were also strongly conserved.

\section{The IHH signalling pathway}

Orthologues of $I H H$ have been identified in other species, such as mice, rats, and chicken, etc. Mouse Ihh and human IHH share an almost identical structure in both signalling domain with $100 \%$ amino acid identity and protein precursor with $86 \%$ amino acid identity, respectively.

It has been demonstrated that Indian hedgehog is neces- 


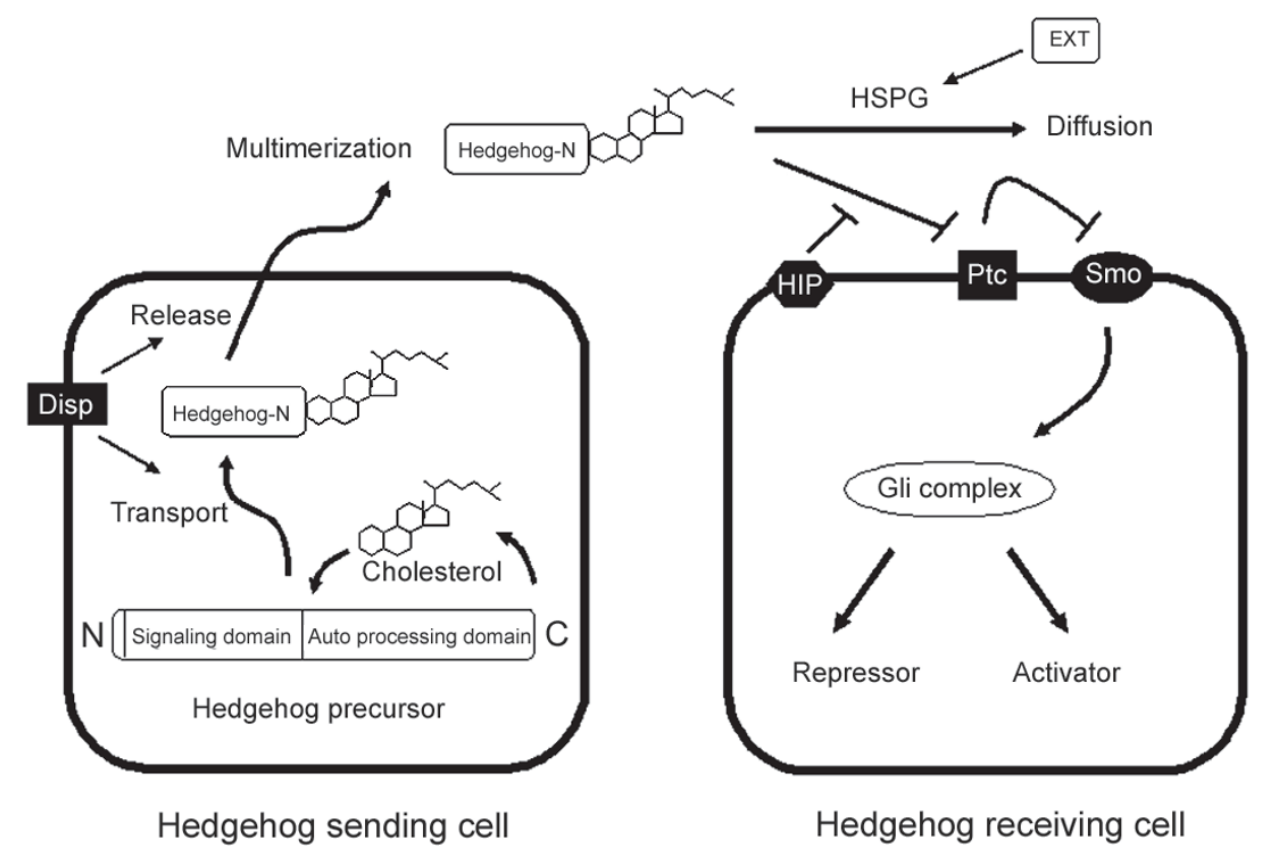

Fig 6. Signalling pathway of Hedgehog.

sary for endochondral bone development, coordinating chondrocyte proliferation, chondrocyte differentiation and osteoblast differentiation through detailed studies on $I h h$ null single and compound mutants engineered by sophisticated genetics techniques[27, 34-36]. Ihh is mainly expressed in prehypertrophic and early hypertrophic chondrocytes. It has been suggested that PTHrP (parathyroid hormone-related protein) mediates the effects of Ihh through the formation of a negative feedback loop[26, 37, 38]. Ihh stimulates chondrocyte proliferation directly and formation of the bone collar by controlling the differentiation of perichondrial osteoblasts. By means of a so far unidentified mechanism, Ihh also up-regulates the expression of PTHrP at the ends of long bones, which prevents chondrocyte from leaving the proliferative pool, and consequently determines the distance between PTHrP-expressing area and Ihh-expressing area (Fig 5). Studies of bone explants in vitro demonstrate how FGF signals interact with the Ihh/PTHrP and the BMP signaling pathways to control chondrocyte development[39].

Upon cleavage, the signaling peptide of Ihh will bind its receptor, Patched. This binding abrogates the inhibitory effect of Patched on Smoothened, leading to activation of a cascade through Gli transcription factors[32]. Like Patched, Hip (hedgehog-interacting protein), another receptor for Hedgehog, is transcriptionally activated in response to Hedgehog signaling; and gain-of-function and loss-of-function experiments indicate that Hip binding of
Hedgehog ligands attenuates Hedgehog signaling[40, 41]. Studies on Drosophila suggest that ttv (tout-velu), a drosophila gene homologous to the mammalian EXT gene family, encodes a glycosaminoglycan transferase involved in the biosynthesis of heparan sulphate proteoglycans (HSPG) that mediates the diffusion of Hh-Np (the cholesterol-modified form of the Hedgehog signaling peptide) in Hedgehog-receiving cells[42]. Recent studies of Dispnull mice indicate that Disp is also required for the transport of Hedgehog protein from its sites of synthesis[43, 44]. It has been demonstrated that cholesterol-modified Hedgehog appears to be required for formation of the secreted Hedgehog multimers that bury their hydrophobic moieties to facilitate the movement[45] (Fig 6).

\section{Discussion and Prospects}

In terms of the known phenotype-genotype relationship, all the above cases can be generally divided into three groups: (1) typical BDA1; (2) mild BDA1; (3) ACFD (suggested to be named by the authors[23]). The consistent features of typical BDA1 are pronounced with shortening of middle phalanges and proximal $1^{\text {st }}$ phalange in varying degrees, and the lack of the middle phalanges. In some cases, no epiphyses in affected children were delineated. For mild BDA1, the middle phalanges in even most affected members are short but not absent. Coned epiphyses are commonly observed in children. (The formation of cone-shaped epiphyses represents the initial stage 


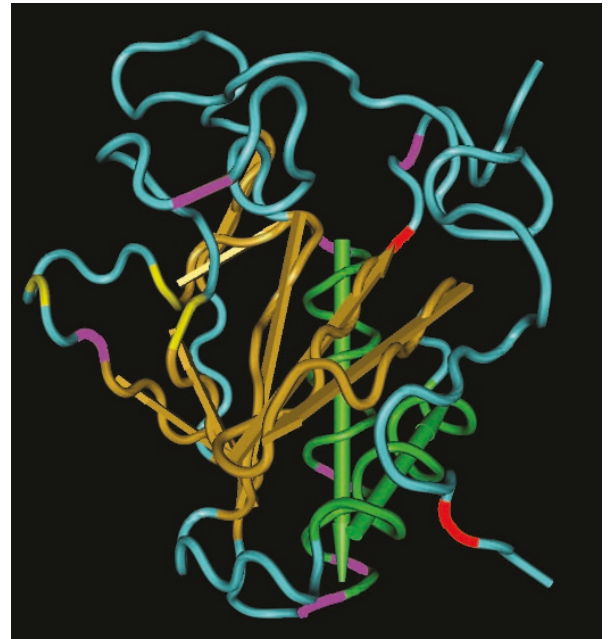

Fig 7. 3D structure based on mouse Shh. The yellow color refers to the positions of three BDA1 mutations. The red color refers to the ACFD mutations. The purple color refers to the sites of HPE3 mutations.

of premature epimetaphyseal fusion resulting in growth plate disappearance before puberty and shortening of the bone involved.) Like mild BDA1, ACFD is characterized by cone-shaped epiphyses and pronounced shortening but no absence of middle phalanges (Fig 2). More severe skeletal dysplasia is presented. In spite of the suggested classification, Haws and McKusick'survey (1963)[6] showed that in the hip of Farabee type brachydactyly patients, the articular surfaces were irregular, and the neck of the femur was usually short with a mushroom appearance of the femoral head, which are very similar to the phenotype of ACFD[23] in the hip. The shared or overlapped phenotype may be found in all the cases examined (Fig 3).

Typical BDA1 and ACFD are caused by heterozygous and homozygous mutations in IHH, respectively, while linkage of mild BDA1 to a new locus at 5p13.2-13.3[24] suggests that there is another candidate gene possibly involved in the IHH pathway producing a less severe phenotype. Armour (2002) studied two prime candidates including cadherin- 6 and $N p r 3$ in detail but no significant result observed[24]. However, the unlinked BDA1 family, which appears to have typical BDA1, reported by Kirkpatrick cannot fit into this classification. The suggested third locus was unmapped yet.

In order to compare the locations of those mutations, Gao et al in 2001[17] and Hellemans in 2003[33] have utilized the crystal structure of the signaling peptide of mouse Shh[46] for mutation analyses (Tab 1, Fig 7). In these cases, the mutations were predicted to be clustered together in three locations, carboxy-terminal end, aminoterminal end and a possible groove structure, as demonstrated by adding SHH missense mutations causing HPE3
Tab 1. Location of known mutations in $\mathrm{HH}$.

\begin{tabular}{llll}
\hline Mutation locations Typical BDA1 & ACFD & HPE3 \\
\hline Carboxy-terminal & & V190A & Q105H, E193Q \\
Amino-terminal & P46L & I116F, N120K, \\
& & W122G, W122R \\
A possible groove & E95K, E95G, & & \\
& D100E, D100N, & D93V, H140P \\
& E131K & & \\
\hline
\end{tabular}

(holoprosencephaly 3)[47]. Evidence provided by Fuse (1999)[48] and Pepinsky (2000)[49] hinted that some amino acids were located in the regions less important or important for binding Hedgehog to its receptor, Patched. Nevertheless, those results are not indicative of the effects of the above mutations. Quantification analysis for ligands binding would give us more knowledge about how mutant hedgehog works with its ligands, such as Patched, Hip and potentially others, on the surface of cells. Detecting the change of signalling activity of mutant proteins through the Hedgehog downstream components, such as, Gli, is considered to be more feasible. The mutant amino acids might be important for the transport of IHH mediated by EXT and Disp. In our view, loss or gain of IHH function can be the cause of malformation but it is still difficult to explain why the IHH mutations affect certain specific skeletal elements, rather than the whole skeleton? For BDA1, haploinsufficiency of wild type IHH is a possible reason but heterozygous Ihh knockout mice are reported to show no relevant phenotype, whereas digital abnormalities in the mouse might have been overlooked, or might be strain-dependent.

To fully understand BDA1, it is necessary to distinguish the difference from brachydactyly type C (BDC) and brachydactyly type $\mathrm{B}(\mathrm{BDB})$, which show the similar characteristic defects. BDC can be differentiated from BDA1 in that BDC has involvement with the first metacarpal, whereas BDA1 has a short $1^{\text {st }}$ proximal bone although they both share the typical characteristic defect of shortening of the middle phalanges with short stature and hip dysplasia. Based on the degree of BDA1 involved, digits can be ordered as follows: $3>4>2>5$, whereas digit 4 with BDC is the longest and least involved; and the apparent "hypersegmentation' is classic for BDC but not for BDA1. BDC is caused by mutations in the GDF5 gene (growth/differentiation factor 5, also termed $C D M P 1)[50]$ which is expressed in developing joints and stimulates mesenchymal condensation and cartilage growth in early stage and plays a later role in the organization of joint formation and segmentation events[51]. GDF5 is a member of a sub- 


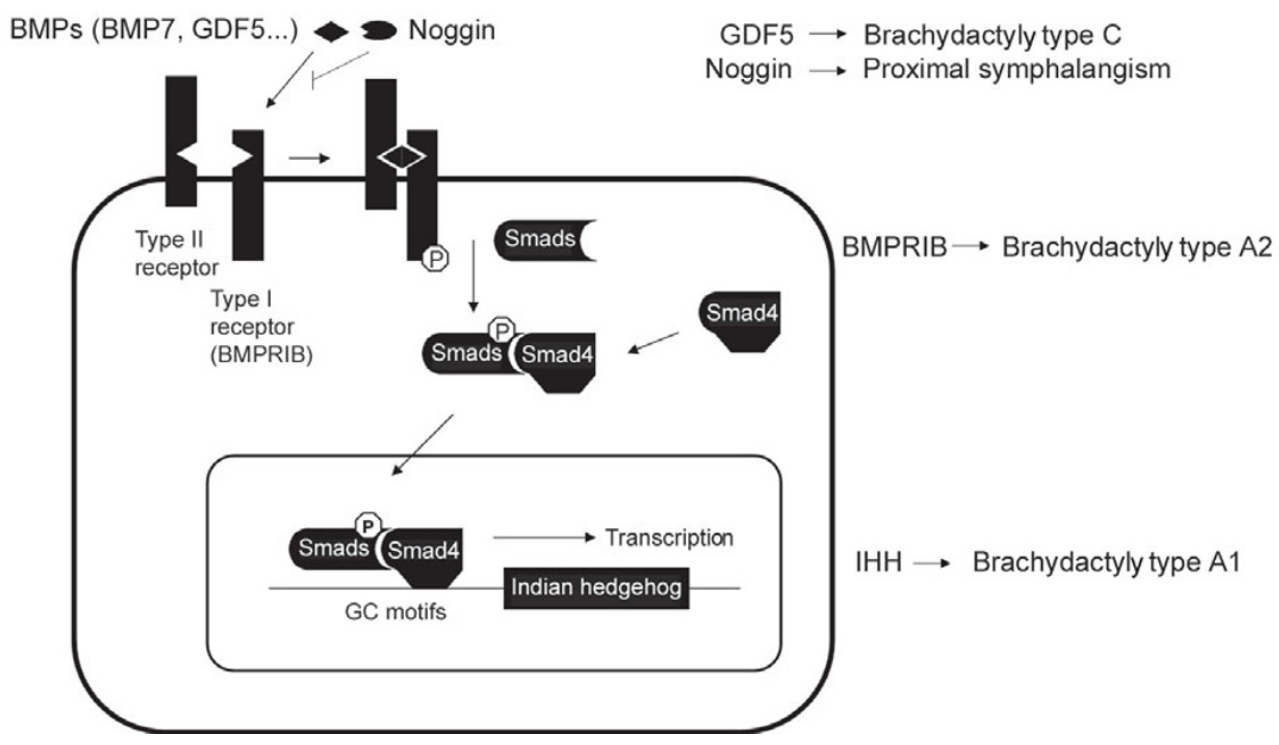

Fig 8. Indian hedgehog is a target of BMP signalling pathway.

group of the BMP (bone morphogenetics proteins) family. Independent experiments suggest that $G d f 5$ and $I h h$ could inter-regulate to determine the joint formation or fusion [51-53]. Thus a complicated interactive cascade appears to exist between BMPs, especially GDF5, and IHH, accounting for maturation and growth of the cartilages and the establishment of boundaries between distal skeletal elements.

BDB's most severe phenotype appears in brachydactylies characterized by terminal deficiency of the fingers and toes. The milder form of it seems to be fusion of the middle and distal phalanges. Dominant mutations in ROR2 (an orphan receptor tyrosine kinase), which is expressed post-natally in articular cartilage, perichondrium, reserve and proliferation chondrocytes, have been identified as causing BDB[54]. Disruption of mouse Ror2 leads to profound skeletal abnormalities[55]. All endochondrally derived bones are foreshortened and misshapen, with a tendency toward greater distal abnormality. As with BDA1, the digits of Ror $2^{-/}$mice were not only shortened, but the middle phalanges were also missing. Ror2 may be involved in Ihh signaling pathway since these two molecules both have critical roles in growth and in the patterning of growth plates and similar phenotype in mutant background.

Lehmann recently published an excellent paper that reports two missense mutations in BMPR1B (bone morphogenetic protein receptor $1 B$ ) causing brachydactyly type A2 (BDA2)[60]. Like BDA1, BDA2 is an autosomal dominant inheritance disease characterized by missing or shortening of middle phalange, but restricted to index finger, with lateral deviation of this finger. To a variable degree, shortening and deviation of the first and second toes was observed. It looks like a mild form of BDA1. Anyway, BDA1, BDA2, BDB and BDC show some overlapping features suggesting IHH, BMPR1B, ROR2 and GDF5 may interact to determine the formation of the phalanges and interphalangeal joints. Studies on BMPR1B and GDF5 mutant mice indicate that combinatorial GDF5/BMPR $1 B$ signalling can regulate chondrogenesis and segmentation of digits[61]. GDF5 binds to BMPR1B with the highest affinity compared with other BMPs[62]. And BMPR1B was showed to be required for Ihh and Glil expression through downregulating Gli2 and Gli3[61]. Interestingly, heterozygous mutations in Nog can also cause multiple joint fusions of phalanges[63]. Noggin (encoded by the Nog gene) is the antagonist of BMPs.

During the time we are preparing this paper, Seki and Hata report their new finding[64] about a direct link between Indian hedgehog and BMP-Smad signalling pathway. CHIP (chromatin immunoprecipitation) based gene cloning experiment identifies $I h h$ as a target gene of BMP. Ihh can be upregulated by BMP or cotransfection of BMP7, Smad1, Smad4 and BMPRIB ${ }^{\text {CA(constitutive active) }}$ due to Smad4 binding to GC-motifs within Ihh promoter region. Their work provides a good explanation of how Ihh and the BMP signaling pathways interact to control chondrocyte development as well as molecular basis of phenotype similarities (Fig 8).

These results may open a new avenue to improve the understanding of the pathway of controlling the formation of joints and phalanges. However, the questions raised include: 1) how the signalling pathway passes the wrong 
message to the interphalangeal joints so accurately? Is it owing to gradient of molecules since both BMP and IHH seem to be morphogen? 2) How Ror2 plays a role in the BMP-IHH signalling pathway? Some unpublished data imply that Ror2 may interact with the BMP-pathway through a negative feed back loop. The answers to the above questions by further analysis of genotype-phenotype will provide important topics for future studies.

\section{ACKNOWLEDGMENTS}

We would like to offer appreciation to the many individuals and organizations that have provided the continued support, guidance and wisdom, including KSE Cheah, Danny Chan and some funding bodies, such as the National Natural Science Foundation of China, and Shanghai Municipality Commission for Science and Technology. This project was supported by NSFC/RGC joint Research Grant ( No. N-HKU705/02) and the Major State Basic Research Development Program of China (No. 2001CB510301). We would also like to thank Dr Michael Keeley for English modification of this manuscript.

\section{REFERENCES}

1 Farabee WC. Hereditary and Sexual Influence in Meristic Variation: A Study of Digital Malformations in Man. Thesis, Harvard University 1903.

2 Drinkwater H. An account of a brachydactylous family. Proc Royal Soc Edin 1908; 28:35-57.

3 Drinkwater $\mathrm{H}$. Account of a family showing minor brachydactyly. J Genet 1912; 2:21-40.

4 Drinkwater H. A second brachydactylous family. J Genet 1915; 4:323-39.

5 Bell J. On brachydactyly and symphalangism. Treasury of Human Inheritance. Cambridge University Press 1951; 1-31.

6 Haws DV, McKusick VA. Farabee's brachydactylous kindred revisited. Bull Johns Hopkins Hosp 1963; 113:20-30.

7 Temtamy SA, McKusick VA. The genetics of hand malformations. Birth Defects Orig Artic Ser 1978; 14(3):1-619.

8 Laporte G, Serville F, Peant J. Type A1 branchydactyly. Study of one family. Nouv Presse Med 1979; 8(50):4095-7.

9 Piussan C, Lenaerts C, Mathieu M, Boudailliez B. Regular dominance of thumb ankylosis with mental retardation transmitted over 3 generations. J Genet Hum. 1983; 31(2):107-14.

10 Tsukahara M, Azuno Y, Kajii T. Type A1 brachydactyly, dwarfism, ptosis, mixed partial hearing loss, microcephaly, and mental retardation. Am J Med Genet 1989; 33(1):7-9.

11 Fukushima Y, Ohashi H, Wakui K, et al. De novo apparently balanced reciprocal translocation between $5 \mathrm{q} 11.2$ and $17 \mathrm{q} 23$ associated with Klippel-Feil anomaly and type A1 brachydactyly. Am J Med Genet 1995; 57(3):447-9.

12 Mastrobattista JM, Dolle P, Blanton SH, Northrup H. Evaluation of candidate genes for familial brachydactyly. J Med Genet 1995; 32(11):851-4.

13 Slavotinek A, Donnai D. A boy with severe manifestations of type A1 brachydactyly. Clin Dysmorphol 1998; 7(1):21-7.

14 Raff ML, Leppig KA, Rutledge JC, Weinberger E, Pagon RA.
Brachydactyly type A1 with abnormal menisci and scoliosis in three generations. Clin Dysmorphol 1998; 7(1):29-34.

15 Armour CM, Bulman DE, Hunter AG. Clinical and radiological assessment of a family with mild brachydactyly type A1: the usefulness of metacarpophalangeal profiles. J Med Genet. 2000; 37(4): 292-6.

16 Yang X, She C, Guo J, et al. A locus for brachydactyly type A-1 maps to chromosome 2q35-q36. Am J Hum Genet 2000; 66(3): 892-903.

17 Gao B, Guo J, She C, et al. Mutations in IHH, encoding Indian hedgehog, cause brachydactyly type A-1. Nat Genet 2001; 28 (4):386-8.

18 den Hollander NS, Hoogeboom AJ, Niermeijer MF, Wladimiroff JW. Prenatal diagnosis of type A1 brachydactyly. Ultrasound Obstet Gynecol. 2001; 17(6): 29-30.

19 Giordano N, Gennari L, Bruttini M, et al. Mild brachydactyly type A1 maps to chromosome $2 \mathrm{q} 35-\mathrm{q} 36$ and is caused by a novel IHH mutation in a three generation family. J Med Genet 2003; 40(2):132-5.

20 McCready ME, Sweeney E, Fryer AE, et al. A novel mutation in the IHH gene causes brachydactyly type A1: a 95-year-old mystery resolved. Hum Genet 2002; 111(4-5):368-75.

21 McKusick V. Mendelian Inheritance in Man. Johns Hopkins University Press 1975.

22 Fitch N. Classification and identification of inherited brachydactylies. J Med Genet 1979; 16(1):36-44.

23 Mortier GR, Kramer PP, Giedion A, Beemer FA. Acrocapitofemoral dysplasia: an autosomal recessive skeletal dysplasia with cone shaped epiphyses in the hands and hips. J Med Genet 2003; 40(3):201-7.

24 Armour CM, McCready ME, Baig A, Hunter AG, Bulman DE. A novel locus for brachydactyly type A1 on chromosome $5 \mathrm{p} 13$. 3-p13.2. J Med Genet 2002; 39(3):186-8.

25 Kirkpatrick TJ, Au KS, Mastrobattista JM, et al. Identification of a mutation in the Indian Hedgehog ( $\mathrm{IHH}$ ) gene causing brachydactyly type A1 and evidence for a third locus. J Med Genet 2003; 40(1):42-4.

26 Vortkamp A, Lee K, Lanske B, et al. Regulation of rate of cartilage differentiation by Indian hedgehog and PTH-related protein. Science 1996; 273(5275):613-22.

27 St-Jacques B, Hammerschmidt M, McMahon AP. Indian hedgehog signaling regulates proliferation and differentiation of chondrocytes and is essential for bone formation. Genes Dev 1999; 13(16):2072-86.

28 Hammerschmidt M, Brook A, McMahon AP. The world according to hedgehog. Trends Genet 1997; 13(1):14-21.

29 Porter JA, von Kessler DP, Ekker SC, et al. The product of hedgehog autoproteolytic cleavage active in local and long-range signalling. Nature 1995; 374(6520):363-6.

30 Porter JA, Young KE, Beachy PA. Cholesterol modification of hedgehog signaling proteins in animal development. Science 1996; 274(5285):255-9.

31 Pepinsky RB, Zeng C, Wen D, et al. Identification of a palmitic acid-modified form of human Sonic hedgehog. J Biol Chem 1998; 273:14037-45.

32 Goetz JA, Suber LM, Zeng X, Robbins DJ. Sonic Hedgehog as a mediator of long-range signaling. Bioessays 2002; 24(2): 57-65.

33 Hellemans J, Coucke PJ, Giedion A, et al. Homozygous mutations in IHH cause acrocapitofemoral dysplasia, an autosomal recessive disorder with cone-shaped epiphyses in hands and 
hips. Am J Hum Genet 2003; 72(4):1040-6.

34 Karp SJ, Schipani E, St-Jacques B, et al. Indian Hedgehog coordinates endochondral bone growth and morphogenesis via parathyroid hormone related-protein-dependent and -independent. Development 2000; 127:543-8.

35 Chung UI, Schipani E, McMahon AP, Kronenberg HM. Indian hedgehog couples chondrogenesis to osteogenesis in endochondral bone development. J Clin Invest 2001; 107:295-304.

36 Long F, Zhang XM, Karp S, Yang Y, McMahon AP. Genetic manipulation of hedgehog signaling in the endochondral skeleton reveals a direct role in the regulation of chondrocyte proliferation. Development 2001; 128:5099-108.

37 Lanske B, Karaplis AC, Lee K, et al. PTH/PTHrP receptor in early development and Indian hedgehog-regulated bone growth. Science 1996; 273:663-66.

38 Chung UI, Lanske B, Lee K, Li E, Kronenberg H. The parathyroid hormone/parathyroid hormone-related peptide receptor coordinates endochondral bone development by directly controlling chondrocyte differentiation. Proc Natl Acad Sci USA 1998; 95:13030-5.

39 Minina E, Kreschel C, Naski MC, Ornitz DM, Vortkamp A. Interaction of FGF, Ihh/Pthlh, and BMP signaling integrates chondrocyte proliferation and hypertrophic differentiation. Dev Cell 2002; 3:439-49.

40 Chuang PT, McMahon AP. Vertebrate Hedgehog signalling modulated by induction of a Hedgehog-binding protein. Nature 1999; 397(6720):617-21.

41 Chuang PT, Kawcak T, McMahon. Feedback control of mammalian Hedgehog signaling by the Hedgehog-binding protein, Hip1, modulates Fgf signaling during branching morphogenesis of the lung. Genes Dev 2003; 17(3):342-7.

42 Bellaiche Y, The I, Perrimon N. Tout-velu is a Drosophila homologue of the putative tumour suppressor EXT-1 and is needed for Hh diffusion. Nature 1998; 394(6688):85-8.

43 Ma Y, Erkner A, Gong R, et al. Hedgehog-mediated patterning of the mammalian embryo requires transporter-like function of dispatched. Cell 2002; 111(1):63-75.

44 Kawakami T, Kawcak T, Li YJ, et al. Mouse dispatched mutants fail to distribute hedgehog proteins and are defective in hedgehog signaling. Development 2002; 129(24):5753-65.

45 Zeng X, Goetz JA, Suber LM, et al. A freely diffusible form of Sonic hedgehog mediates long-range signalling. Nature 2001; 411 (6838):716-20.

46 Hall TM, Porter JA, Beachy PA, Leahy DJ. A potential catalytic site revealed by the 1.7-A crystal structure of the amino-terminal signalling domain of Sonic hedgehog. Nature 1995; 378(6553): 212-6.

47 Wallis D, Muenke M. Mutations in holoprosencephaly. Hum Mutat 2000; 16(2):99-108.

48 Fuse N, Maiti T, Wang B, et al. Sonic hedgehog protein signals not as a hydrolytic enzyme but as an apparent ligand for patched.
Proc Natl Acad Sci 1999; 96(20):10992-9.

49 Pepinsky RB, Rayhorn P, Day ES, et al. Mapping sonic hedgehog-receptor interactions by steric interference. J Biol Chem 2000; 275(15):10995-1001.

50 Polinkovsky A, Robin NH, Thomas JT, et al. Mutations in CDMP1 cause autosomal dominant brachydactyly type C. Nat Genet $1997 ; \mathbf{1 7 ( 1 ) : 1 8 - 9}$

51 Storm EE, Kingsley DM. GDF5 coordinates bone and joint formation during digit development. Dev Biol 1999; 209(1):11-27.

52 Merino R, Macias D, Ganan Y, et al. Expression and function of Gdf-5 during digit skeletogenesis in the embryonic chick leg bud. Dev Biol 1999; 206(1):33-45.

53 Francis-West PH, Abdelfattah A, Chen P, et al. Mechanisms of GDF-5 action during skeletal development. Development 1999; 126(6):1305-15.

54 Oldridge M, Fortuna AM, Maringa M, et al. Dominant mutations in ROR2, encoding an orphan receptor tyrosine kinase, cause brachydactyly type B. Nat Genet 2000; 24(3):275-8.

55 DeChiara TM, Kimble RB, Poueymirou WT, et al. Ror2, encoding a receptor-like tyrosine kinase, is required for cartilage and growth plate development. Nat Genet 2000; 24(3):271-4.

56 Sillence DO. Brachydactyly, distal symphalangism, scoliosis, tall stature, and club feet: a new syndrome. J Med Genet 1978; 15(3):208-11.

57 Hoeffel JC, Didier F, Chantereau D, Medoc JM, Muller JP. Metaphyseal dyschondroplasia with cone-shaped epiphyses. Br J Radiol 1987; 60(715):707-10.

58 Nissen K. A study in inherited brachydactyly. Annals of Eugenics 1933; 5:281-301.

59 Hoefnagel D, Gerald PS. Hereditary brachydactyly. Ann Hum Genet 1966; 29(4):377-82.

60 Lehmann K, Seemann P, Stricker S, et al. Mutations in bone morphogenetic protein receptor $1 \mathrm{~B}$ cause brachydactyly type A2. Proc Natl Acad Sci USA 2003; 100:12277-82.

61 Baur ST, Mai JJ, Dymecki SM. Combinatorial signalling through BMP receptor 1B and GDF5: shaping of the distal mouse limb and the genetics of distal limb diversity. Development 2000; 127:605-19.

62 Nishitoh H, Ichijo H, Kimura M, et al. Identification of type I and tpe II serine/threonine kinase receptors for growth/differentiation factor-5. J Biol Chem 1996; 271:21345-52.

63 Gong YQ, Krakow D, Marcelino J, et al. Heterozygous mutations in the gene encoding noggin affect human joint morphogenesis. Nat Genet 1999; 21(3):302-4.

64 Seki K, Hata A. Indian hedgehog gene is a target of the bone morphogenetic protein signaling pathway. J Biol Chem 2004; in press.

Supplementary Information accompanies this paper on www.cell-research.com 